\title{
Using design rules to guide the PSS design in an engineering platform based on the product service lifecycle management paradigm
}

\author{
Claudio Sassanelli* \\ Department of Economics, Management and Industrial Engineering, \\ Politecnico di Milano, \\ Via R. Lambruschini 4/b, 20156, Milano, Italy \\ Email: claudio.sassanelli@polimi.it \\ *Corresponding author

\section{Giuditta Pezzotta, Fabiana Pirola and Roberto Sala}

\author{
Department of Management, Information and Production Engineering, \\ University of Bergamo, \\ Viale Marconi, 5, Dalmine (BG), 24044, Italy \\ Email: giuditta.pezzotta@unibg.it \\ Email: fabiana.pirola@unibg.it \\ Email: roberto.sala@unibg.it
}

\section{Antonio Margarito, Mariangela Lazoi and Angelo Corallo}

Dipartimento di Ingegneria dell'Innovazione, Università del Salento, Campus Ecotekne, 73100 Lecce, Italy Email: antonio.margarito@unisalento.it

Email: mariangela.lazoi@unisalento.it

Email: angelo.corallo@unisalento.it

\section{Monica Rossi and Sergio Terzi}

Department of Economics, Management and Industrial Engineering, Politecnico di Milano,

Via R. Lambruschini 4/b, 20156, Milano, Italy

Email: monica.rossi@polimi.it

Email: sergio.terzi@polimi.it

\begin{abstract}
Nowadays, product service systems (PSSs) and smart products are surging in the market and acquiring a strategic role for companies' survival. Manufacturers, compelled towards the transformation process into PSS providers, have to face the challenge of building up knowledge for successfully providing such complex solutions, also resorting to the help of more effective
\end{abstract}


IT systems and tools. The need to adopt a collaborative design platform is starting to be raised also in the PSS context, since companies often have a lack of knowledge for providing PSS. This work, grounded on a combination of lean and DfX-based theories, is aimed at improving the knowledge formalisation and sharing with the support of IT tools. In this sense, the lean design rules tool (LDRT), able to manage the PSS design knowledge generated is proposed and integrated in a more holistic engineering environment able to interact with product lifecycle management (PLM) systems.

Keywords: product-service system; PSS; PSS design; Design for X; DfX; knowledge management; lifecycle management; Lean Design; DfX tool.

Reference to this paper should be made as follows: Sassanelli, C., Pezzotta, G., Pirola, F., Sala, R., Margarito, A., Lazoi, M., Corallo, A., Rossi, M. and Terzi, S. (2018) 'Using design rules to guide the PSS design in an engineering platform based on the product service lifecycle management paradigm', Int. J. Product Lifecycle Management, Vol. 11, No. 2, pp.91-115.

Biographical notes: Claudio Sassanelli received his $\mathrm{PhD}$ in Management, Economics and Industrial Engineering from the Politecnico di Milano. During this period, he has held Visiting Researcher positions from the Tokyo Metropolitan University (TMU) and Universidade de São Paulo (USP). His main research interest is product service system (PSS) design, specifically addressing to product lifecycle management and design for $\mathrm{X}$ (DfX) approaches. He received his Bachelor's and Master's in Management Engineering in 2010 and a second Bachelor's and Master's in Civil Engineering in 2013, both from the Politecnico di Bari.

Giuditta Pezzotta is an Assistant Professor from the Department of Management, Information and Production Engineering - University of Bergamo. Through her work at the University of Bergamo, she has been involved in several industrial and research projects related to product-service. She coordinated the ProSSaliC project financed European Project - IRSES EC Marie Currie action. She is technically coordinating the DIVERSITY project, a H2020 funded project in the area of product-service engineering. Her current research interests are service engineering, product-service system and PSS in the Industry 4.0 migration. She is the author of more than 40 refereed international journals and conference papers.

Fabiana Pirola is a Research Assistant at the University of Bergamo (Italy). She holds a Master's in Management Engineering and $\mathrm{PhD}$ in Logistics and Supply Chain Management from the University of Bergamo. In 2008, she joined the International Logistics Program - Master of Engineering in Logistics and Supply Chain Management at MIT-Zaragoza Logistics Center in Spain. In 2010, she has been a $\mathrm{PhD}$ visiting student at the Bowling Green State University (Ohio, USA). She is a member of the CELS - Research Group on Industrial Engineering, Logistics, and Service Operations from the University of Bergamo (http://cels.unibg.it). Her main research area is PSS and service engineering.

Roberto Sala graduated in 2016 in Management Engineering with a Master thesis on the investment models for the renewable energy market at Politecnico di Milano. Currently he is a PhD student in Technology, Innovation and Management (TIM) from the University of Bergamo. His research activities gravitate around Industry 4.0 and product-service systems. 
Antonio Margarito is a Software and Computer Engineer. Since 2010, he is a Research Fellow from the Università del Salento. He got both a Bachelor's and Master's in Computer Engineering from the Università del Salento.

Mariangela Lazoi received her $\mathrm{PhD}$ in e-business from the University of Salento, Lecce, in 2009. She is an Assistant Professor with the Department of Engineering Innovation, University of Salento. She is involved in national and international research projects on product design methods and tools, and on product lifecycle management. She has experience in the definition of processes according to international architecture frameworks and organisational context features. She has a wide experience in the analysis of complex industrial sectors, mainly matured during exploration and exploitation studies in aerospace companies and Apulia aerospace district.

Angelo Corallo received his MSc in Physics from the University of Lecce, Italy, in 1999. He is an Associated Professor from the Department of Innovation Engineering, University of Salento, Lecce. His main research interests include technologies and organisational strategies in complex industries, knowledge management, and collaborative working environments. $\mathrm{He}$ is the Coordinator of several research projects, funded by the EC under FP6, FP7 and H2020 or by Italian National Research funds (e.g., X@Work, OPAALS, DISCORSO, MAIS, KIWI, TEKNE, X-Net-Lab, KHIRA, Digital Business Ecosystem (DBE); PRACTICE, SECURESCM, CRESCENDO, TOREADOR). He is also the author of more than 90 publications.

Monica Rossi received her MSc in Management Engineering from the Politecnico di Milano, Milan, Italy, in 2010. She is currently an Assistant Professor with the Department of Management, Economics, and Industrial Engineering, Politecnico di Milano. She currently teaches product lifecycle management. She is engaged in research on lean product and process development (LPPD) and product lifecycle management (PLM). She is also actively engaged in research, industrial, and European projects, and training and teaching activities on PLM and LPPD. She is author of more than 60 national and international publications. She received the Shingo Prize for her book chapter in The Routledge Companion to Lean Management (Routledge, 2017).

Sergio Terzi is an Associate Professor of Product Lifecycle Management from the Politecnico di Milano, Department of Economics, Management and Industrial Engineering. He got his degree in Industrial Engineering in 1999, Master's in Business Administration in 2001 and PhD in 2005 (on the topic of product lifecycle management). He is the author of four books and more than 150 papers at national and international level. He is a member of the editorial board of the International Journal on Product Lifecycle Management and of the IFIP WG 5.1 and 5.7. He is one of the Founders of International Conference on Product Lifecycle Management. He is used to work on international and national research projects, generally with dissemination and exploitation responsibilities. He is the scientific responsible for both the LeanPD Italian Community, and the GeCo Observatory (observatory on management of collaborative design processes) in the School of Management of Politecnico di Milano. 


\section{Introduction}

Manufacturing companies in the last decades started reacting to the market evolution with a new paradigm constituted by products and services coupled and sold as a unique entity - the product-service system (PSS). Goedkoop et al. (1999) state that PSS components (product, service, supporting infrastructure and network) are jointly able to fulfil the customers' needs, pointing out that they can be equally important for this scope. Generally, PSSs are made to pursue multiple objectives as industrial competitiveness, customer satisfaction and also sustainable development (Tukker and Tischner, 2006). In order to satisfy the different needs and expectations these systems are supposed to meet, the importance of the design phase has been evidenced in literature Tukker and Tischner (2006), Mont and Lindhqvist (2003) and Sassanelli (2015a). However, product and service features are generally designed by companies as two separate elements. Substantial enhancement in their features and characteristics will indeed occur only if some changes arise along the way this phase is conducted (Sassanelli et al., 2016). Involving all the significant stakeholders since the early phases of the design stage and supporting a collaborative working mode to facilitate product engineers and designers and service managers is essential to establish a collaborating design team and to set commonly agreed basis and directions. Only in this way companies can be led to effectively manage all the heterogeneous and scattered knowledge deriving by a melting pot of skills, competences, data and resources. Moreover, manufacturers, pushed towards the transformation process into a PSS provider (Vandermerwe and Rada, 1988; Brax, 2005) have to face the challenge of building up knowledge for supporting an integrated design of tangible and intangible parts in their solutions and thus be able to successfully providing new services (Schenkl et al., 2014). The relevance of an effective knowledge management (KM) (Grover and Davenport, 2001) often suggests the adoption of IT solutions to handle more effectively and efficiently the intellectual capital of a company: so far, in the PSS context, collaborative design platforms have been proposed but only limited to typically ease the engineering processes (Garetti et al., 2012; Cenamor et al., 2017). However, manufacturing companies often have a lack of procedure and knowledge for managing the collaborative design of simple products (Huang, 1996) issue leading to even bigger challenges for the PSS (Schenkl et al., 2014; Wallin et al., 2013). For these reasons, an improvement in knowledge formalisation, collection, sharing and reuse among product design and service management functions supported by IT tools is needed. This would also support standardisation practices in the PSS design process fostering continuous improvement consciousness (Sassanelli et al., 2015a). Indeed, from one side the PSS development process could benefit thanks to more structured internal industrial procedures and better common understanding among divisions, from the other the codified knowledge could constitute a shared and well protocolled source of best practices adopted in the design phase to solve problems. To this purpose, the design for product service supportability (DfPSSu) approach has been proposed in Sassanelli et al. (2016), stimulating designers and engineers and impelling them to face in a concurrent and synergic way all the different aspects they have to consider during the PSS design. The DfPSSu approach has been generated through an in-depth literature review of several Design for X (DfX) research works, obtaining a list of approach suitable in the PSS context and for each of them the definitions, the main principles, the most relevant techniques and the main guidelines and rules already available in Sassanelli et al. (2016). It mainly aims at supporting designers in making the product and the supporting 
infrastructure more adequate to support the service delivery. In this perspective, the PSS design GuRu methodology, generating DfPSSu generic guidelines and specific rules enabling a more collaborative design of the PSS, has also been proposed (Diversity Project, 2017) with the objective of assisting manufacturers in making their first step towards servitisation. The industrial value and the approach validity have been verified in different cases presented in Diversity Project (2017), Sassanelli et al. (2017a, 2017b).

From a theoretical point of view, as proposed in the PSS Lean Design methodology (PSSLDM), Diversity Project (2017) aimed at aiding PSS development from the customer analysis to the offering analysis, design guidelines can be considered a trait d'union between the concept and detailed design phases, integrating the product and service components and being able to consider both providers' constraints and customers' needs. They are also a mean to bond PSS design phases, from its conception to the detailed design and configuration management. However, as resulting from the application cases (Diversity Project, 2017; Sassanelli et al., 2017a, 2017b), a supporting software tool able to manage the knowledge produced in terms of DfPSSu guidelines and rules through the methodology and to support the designer in an effective use of such knowledge along the PSS design process, is fundamental. It would help companies in reducing the issues due to:

1 wrong design interpretations

2 the creation of solutions not compliant with what required both in terms of product and service features

3 re-works and defectiveness of both the products and the services offered.

These drive to a reduction of the time to market as specified in the business cases requirements (Diversity Project, 2016). This heavily affects the customer perception of the company, fostering the customer loyalty and also the company performances.

Moreover, this formalised knowledge can contribute to practically support the interaction of the different design procedures and the related IT tools occurring along the PSS development process. In this sense, the necessity to raise the awareness and to start a discussion on the possible changes needed by current product lifecycle management (PLM) models, also thanks to the support of DfX approaches, was recently highlighted by Diversity Project (2017). Currently, PLM models do not manage the lifecycle of a PSS (Diversity Project, 2017). Indeed, extant PLM tool's functionalities can be grouped according to the Technoware-IT, Infoware, Functionware, Orgaware (TIFO) framework and further divided into sub-criteria (Savino and Mazza, 2012): in the Functionware area, no function aimed at a practical integration of product and services can be detected. PLM, as of now, are focused only on product design, neglecting an integrated management of service information. The inverse stands true for service lifecycle management (SLM) (Diversity Project, 2017). Thus, an adapted PLM/SLM may give support in enabling such integration within the PSS context. This new concept would allow to integrate all information along the new extended PSS lifecycle and its utilisation by the different actors involved through the appropriate addresses. For example, through new product service data/lifecycle management (PSDM/PSLM) concepts, the activities and the resources needed to deliver the service can be directly connected to the bill of materials (BoM) of the connected product and these links can be further supported and explained by related DfPSSu guidelines and rules. Indeed, a critical aspect related to the design of 
PSS, is the necessity to give emphasis to approaches able to capture, manage and share product lifecycle information and data with service lifecycle information in an effective way.

Therefore, this paper wants to clarify how the generation, use and re-use of guidelines and rules, belonging to the DfPSSu approach, could support the entire development process of PSSs, highlighting their importance in aiding a concurrent design process, based on effective KM. Thus, first of all, in Section 2, the paper introduces the theory combining lean and DfX approaches presenting the concepts of lean content design guidelines and rules, also clarifying the purpose of this work. Then, Section 3 presents the research design adopted to develop the Lean Design rules tool (LDRT). Section 4 explains the functionalities of the developed tool, aimed at managing the created knowledge. The value of this tool is further empowered thanks to the possibility to interact with PLM systems through its integration into an engineering environment, Pezzotta et al. (2016) developed and built within the DIVERSITY project, to effectively develop PSSs. Indeed, in order to create this interaction, based on the necessity of managing both product and service components, the new PSDM/PSLM tool is introduced. Authors want indeed to highlight and explain design guidelines' function in a platform approach, enabling the integration of the previously proposed tool with the PSDM/PSLM tools: to this aim a systematic design and engineering workflow, to be followed during the PSS design in order to fully exploit guidelines benefits, is proposed in Section 5. Finally, after reporting the validation of the LDRT in Section 6, conclusions delineate the strengths and weaknesses of the research, also indicating the possible next steps in this research stream.

\section{Research context and aim}

Lean and DfX concepts have been considered as a valuable way to support the collaborative and concurrent design of a PSS since the early phase of the development process (Dombrowski and Schmidt, 2013). They are also considered to be able to trace the design rationale that is the fundamental requirement to afford changes management and to support the progressive by least commitment convergence of the space of design solutions (Roucoules and Tichkiewitch, 2015). On this path the lean content guidelines and rules belonging to DfPSSu approach have been defined and validated in industrial environment (Sassanelli, 2017a, 2017b) raising the industrial need to understand how to better manage and use such formalised knowledge (Gatenby and Foo, 1990) on a daily basis.

The integration between DfX approaches and Lean Design theory to create design guidelines has been one of the starting points of this research.

DfX is an integrated approach to design products and processes for cost-effective, high-quality downstream operations from design and manufacture (including fabrication, assembly and test) to disposal. More specifically, Design (or D) in DfX is interpreted as concurrent design of products, and associated processes and systems. Instead, X in DfX stands for $x+$ bility, i.e., life cycle process/certain product characteristics (x) + performance measures (bility) (Huang, 1996). Indeed, the PSS complexity and variety require knowledge that could aid designers to better achieve different abilities. In this sense, according to Chiu and Okudan (2010), DfX application provides an important contribution by defining the concept of guidelines. They are intended as a set of 
recommended design practices that include broad design rules and specific implementation strategies, informing the design team of ways to optimise a design or to minimise costs for the lifecycle phase under consideration.

On the other hand, qualitative Lean Design guidelines help designers to streamline the design process, even with a lifecycle view in certain cases (Huthwaite, 2012; Moxham, 2005) optimising the development process rather than product design and thus not providing to designers product design instructions on an adequate level of detail (Dombrowski and Schmidt, 2013; Dombrowski et al., 2014). DfX guidelines are hence more operative, giving specific instructions on how to deliver and enhance a virtue or a stage along the lifecycle (Bauer and Paetzold, 2006).

Based on the reference framework proposed in literature by Dombrowski et al. (2014), an integration of DfX approaches in the concept of Lean Design has been proposed for enhancing the serviceability of the product. The aim is to support the service provision since the PSS development phase, using DfX approaches under a lean perspective, as a connection to derive the required product properties (e.g., user-friendliness, maintainability) (Dombrowski et al., 2014) from an appropriate set of concrete product characteristics (e.g., dimensions, materials, structure or shape) and inverted.

In the PSS context, a further step is needed in order to fully exploit DfX benefits. DfPSSu approach (Sassanelli et al., 2016; Diversity Project, 2017) was defined as a synergic use of several criteria that should be satisfied during the whole PSS lifecycle in order to meet the different stakeholders' needs. It also tries to solve the open issue of systematically integrating product and service components, mainly making the product and supporting infrastructure parts more suitable to support the service during their lifecycle. Indeed, lean content design guidelines and rules, clearly referring and belonging to this approach, compared with traditional DfX approaches, focus not only on both the tangible and intangible aspects but act also on their interconnection, integrating them and guaranteeing the switch to specific indications for PSS designers. Moreover, they are able to focus on both the customer and the provider perspective along the entire PSS lifecycle: they reveal to be capable of capture, manage and share product lifecycle information and data in an effective sector-specific way (Diversity Project, 2017; Sassanelli, 2017a).

Design guidelines provide a proper basis for considering generic, non-company-specific, lifecycle oriented information to be followed during the design phases (Hepperle et al., 2011). Such guidelines can evolve and be applied to the specific company issues of either a product/service/system or a specific component, leading toward the creation of the connected design rules that become concrete and quantitative instructions for engineers, designer and project managers to be followed during their daily specific design activities. The set of design rules represents hence the knowledge characterising and belonging to the company. Furthermore, this representation can enhance how design knowledge is managed, fostering both its exchange among the different members of the design team, mainly between product engineers and sales personnel, and its reuse for future design projects. In particular, guidelines are formalised based on the ability (Mital et al., 2008) they want to satisfy.

A rule is directly connected to a guideline, being in charge of developing the generic indications expressed in the guideline in a more operative and focused way, specifying that knowledge for a specific company and PSS. In order to perform this, a specific 
methodology has been developed aiming at guiding the designers in the definition and assessment of the guidelines and rules (Diversity Project, 2017).

In order to better clarify the concepts of such intangible assets, an example of design guidelines and (connected) rules is reported hereafter.

- Lean content design guideline

a Use visual cues for linking different modular components during installation.

- Lean content design rules

a Use pins in different positions for each layer as visual cues for linking different modular components during installation.

- Design guidelines and rules can be developed mainly when

1 a new PSS is entirely developed from both the product and service side

2 a new PSS, composed by an already existing product to which is added a new service, is developed

3 the PSS is re-designed or needs improvements due to a problem occurred during its lifecycle.

Design guidelines and rules are more effective if deriving from the interaction of workers with different skills in a multidisciplinary team (Winner et al., 1988). This group should be able to adopt the methodology to both conduct the new design of the PSS according to a problem-solving procedure and generate content design guidelines and rules. Furthermore, thanks to a consistent protocolling of such developed knowledge, the different sub-departments and components of the team, focused on specific topics of the same design project, can be aligned on every aspect every time a design modification of the design project is needed.

Thus starting from the general requirements of the methodology generating design guidelines and rules, a strictly related IT tool is needed to support the protocolling and the efficient use and re-use of such knowledge in the innovation process of PSSs. For this purpose the LDRT has been created, heavily based on the characteristics of the methodology generating design guidelines and rules (Diversity Project, 2017) to constitute a repository, able first of all to support the KM of the PSS design project and also to interact with both the PLM system and the DIVERSITY platform since these are able to cover all the stages composing the PSS development. Thanks to this, Guideline and Rules become the core pillar to connect the product and the service dimensions, also gauging how much they contribute and impact, both in a positive and a negative way, on each phase of the PSS lifecycle phases [through lifecycle process (LP) assessment during the rules generation (Diversity Project, 2017)]. At the same time, this tool needs to be simple and to have a user-friendly interface, aiding the users (designer, engineers, developers and managers) to effectively input and manage the PSS design knowledge created during the design phase.

The aim of this research is to put into evidence how such a tool and the lean content design guidelines and rules can effectively support the KM and the collaborative design along the entire PSS development process, also raising and fostering the need to change the current PLM models to support companies along the PSSs lifecycle. In this sense, the work explains how the PSDM/PSLM tools, an extension of the most commons PDM/PLM tools, integrated in the PSS development engineering environment, support 
design knowledge in getting a strategic role along the entire development process of the PSSs. More specifically, the PSDM/PSLM tools intervene in the design and/or redesign of new product features or of a new product, enabling the PSS development defined in the concept phase. In the design phase, companies have been already well defined tools and design methods: the most common are those grouped under the umbrella of PLM systems (Corallo et al., 2013). The integrated development of a product and related services requires the LDRT to support a methodology and appropriate tools to keep the PSS configuration updated during all stages of development.

Indeed, compared to the LDRT, so far, the other existing PSS design and engineering tools, as for example those composing the Service Explorer (Sakao et al., 2009) or the ServLab (Meiren and Burger, 2008), are not able to consider the PSS development in all its complexity (Pezzotta et al., 2014) since their only focus is to add the service components without considering the product lifecycle perspective. The PSS design and engineering tools so far proposed have not been created to guide PSS designers and engineers with step by step indications along the development process and to give them also the opportunity to verify the consistency of such knowledge generated and used. This can instead be offered by the LDRT, thanks to its two main functions, the create and the search lean content design guidelines/rules.

Figure 1 Research methodology for the tool development (see online version for colours)

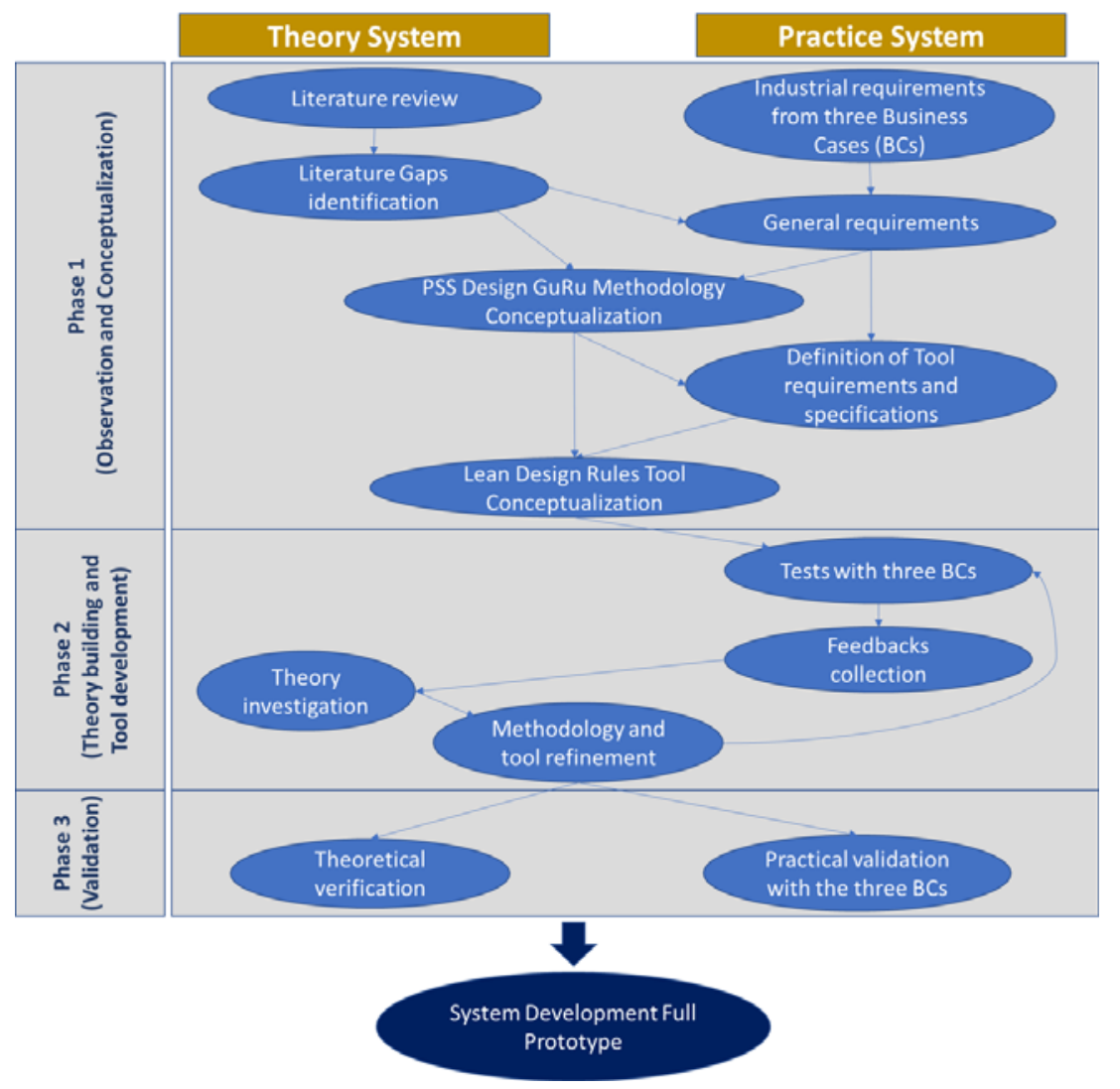


Moreover, PLM systems need to be involved, since, by properly merging the methods, models and tools, they could be able to manage the entire design process by considering the service components since the early design phase.

Therefore, in the following, the research methodology adopted to develop this tool, that is strictly coupled and linked to the methodology generating the knowledge it is responsible to manage (Diversity Project, 2017) is going to be presented.

\section{Research methodology}

The LDRT has been developed using as starting point the PSS design GuRu methodology (Diversity Project, 2017) referring to the DfPSSu approach (Sassanelli et al., 2016). Requirements for the methodology development had been derived following interactive and interpretative principles, involving thus experts belonging to three selected application cases. In particular, a research methodology has been designed (see Figure 1) to develop first the methodology and then the connected tool.

Furthermore, DfX shell (Huang, 1996; Huang and Mak, 1997), a procedure inspired to the PARIX model (Duffey and Dixon, 1993) to develop DfX driven tools, has been considered along the entire research design and conduction. It leads the authors along the whole tool development: from the analysis of (functional, operability and focus) requirements, through the product and process modelling and compilation of DfX manuals and workbooks, to the verification.

The team involved in this research was constituted by researchers and employees put together to have both a theoretical and practical perspective: four academics with a background in product development, PLM, service and PSS development, interacted with heterogeneous teams, in terms of experience and roles related to product development and service management, from the companies' side. Indeed, three companies, constituting the sample used to previously develop the methodology, were involved to develop the tool and evaluate the integration level among the different tools composing the developed engineering environment (Diversity Project, 2017; Sassanelli, 2017a). To achieve this last objective, three milestones have been identified (tools' early development, platform's early prototype and platform's full prototype). In particular, the first phase, following interpretivist research (Williamson, 2002) and dealing with observation and theory building, was aimed at the early development of the tool, detecting the companies' necessities, the functional and non-functional requirements and the functional and technical specifications. Then, experimentation was repeatedly conducted, in three iterations, to develop the prototype that represented, along the research time lapse, both a proof of concept and a basis for continuing the development of the tool. Indeed, in each of the conducted application cases, some suggestions and feedbacks were obtained to improve not only the tool itself (in its functionality and usability) but also its consistency and compatibility with the methodology for generating guidelines and rules. Moreover, also its integration level in the simultaneously developed engineering environment was improved, and, in terms of usability, some suggestions for improvements were easily obtained exploring the tool functionalities in the company context. Finally, the platform's full prototype was obtained testing in the three cases the overall functionality of the platform and its interaction with the tools. Thus, in each one of the three macro-phases constituting the system development, three iterations involving at least three employees internal to the companies were conducted. 
Along the entire process, as described more in detail in Diversity Project (2017), different research traditions [in particular applied, practical research (Potts, 1993), interactive research (Ellström, 2007), system development (Nunamaker and Chen, 1990) and quality research design (Williamson, 2002)] have been used and integrated in the whole research process to give rigorousness and relevance for both academia and industries to the research and to its results.

Therefore, the next paragraph is dedicated to the description of the LDRT, deeply linked to the methodology generating such knowledge (Diversity Project, 2017) raising the needs related to its introduction and explaining its structure and its main functions.

\section{The main feature of the LDRT}

As previously stated, the LDRT has been created to be an effective tool for KM. Indeed, since it has been developed in couple with the PSS design GuRu methodology (Diversity Project, 2017; Sassanelli, 2017a, 2017b) along the PSS detailed design process, it eases the storage and management of such design knowledge. The tool aims at enhancing the collaborative design of a PSS through a better exchange of knowledge between product and service functions. In this sense, it is aimed to aid users in the PSS design, overcoming the product-centric perspective typical of manufacturing companies. As a result, it can store valuable knowledge and convert them in wisdom belonging to the company (Ackoff, 1989) to be shared along space (in terms of employees, design teams, divisions, companies and sectors) and time (overwhelming issues deriving by employees rotation and changes) for supporting PSSs and smart products design and management.

This knowledge, which is created by multi-disciplinary teams, is hence supposed to be shared and made available to companies' employees belonging to different divisions but cooperating in a concurrent way to develop the new PSSs. However, the organisation of such heterogeneous teams is a critical aspect for achieving effective DfX, due to both sociological and technological problems (Demarco and Lister, 1987): it is indeed complex to obtain jelled collaborating teams composed by people from different functions (Gatenby and Foo, 1990). This can depend on the need of effective communication essential for team work to create, use and re-use the DfX knowledge base (Gatenby and Foo, 1990). Thus, to effectively manage this knowledge and foster and ease the PSS innovation process, guidelines and rules need to be consistently codified and protocolled to be easily stored, used and re-used along the time by PSS designers and engineers. For example, a correct use of tags and others filters through the tool, applied on such a knowledge, is functional to improve the transversal degree of applicability of the high level design guidelines on different PSSs. Moreover, the LDRT can be very important to ease the collaboration among the components of a design team during the innovation process of a PSS: through it all the employees are supposed to be catered with the same knowledge, improving the possibilities to innovate in a concurrent way the PSS under analysis. At this purpose, filters and tags can enable employees to search and find efficiently the desired knowledge, avoiding wastes of time and useless effort in the design phase and addressing designer's lack of knowledge (Sundin, 2009; Tan et al., 2010) in important PSS lifecycle areas. Guidelines and rules can be filtered also per author, referring product/service/components, ability and tags: according to the different information available, the design knowledge can be retrieved efficiently and effectively, 
fostering collaboration in the company independently by the kind of organisation involved.

Moreover, to best fit the generation and codification processes of such knowledge, the tool has been developed in couple with the methodology generating DfPSSu guidelines and rules, adopting for both the same research design and procedure (Diversity Project, 2017) in a simultaneous way: after the analysis of both the literature and practice, gaps in PSS design have been detected and an interpretation of the context has been proposed, getting to the definition of the requirements and specifications needed for the development of the tool. According to system development research tradition (Nunamaker and Chen, 1990), theory building, observation and experimentation were all used to develop the tool prototype that constituted, along the research time lapse, both a proof of concept and a basis for continuing research. Therefore, after the definition of requirements and specifications in an interactive and interpretative way (Williamson, 2002; Ellström, 2007), the sub-system architecture of the tool has been built: the LDRT is a group comprising three components that work together to support the management of design guidelines and rules and their validation during a design project. The three components, namely lean design rules, associate design rules and validate PSS design, belong to the same group because they share the same model and they manage the business logic related to guidelines and rules, even if the data flow among them is almost nil, because they work by sharing information through the database, as depicted in Figure 2.

Figure 2 Components of the Lean Design rules group (see online version for colours)

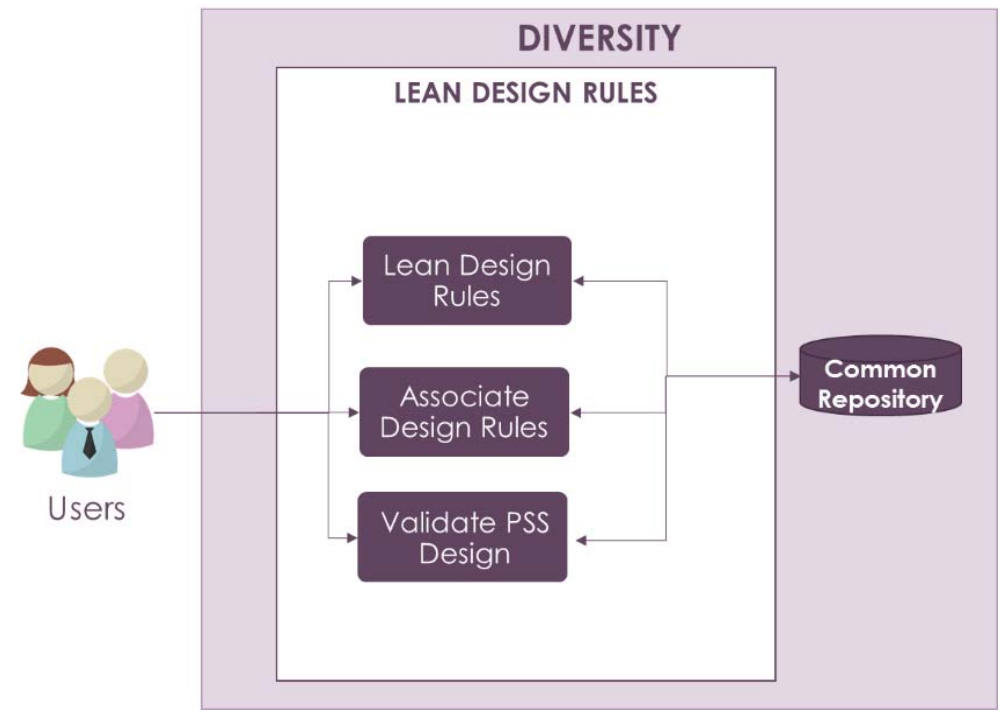

The main features of the tool, distributed among the three components, are as following:

- the Lean Design rules component is the one managing the creation, editing, viewing, deleting and searching for guidelines and rules

- the associate design rules component allows the designers to associate lean content design guidelines/rules to a design project 
- the validate PSS design component validates the design outputs by checking if guidelines and rules associated with a design project have been all implemented.

The main scenario thought for the use of this tool is composed of six steps. Applying the PSS design GuRu methodology, the designer generates and collects the necessary information and:

1 identifies the new design knowledge to insert in the repository

2 defines if it is a lean content design guideline or rule

3 inputs the guideline/rule and the information needed to classify it

4 saves the guideline/rule

5 needs to retrieve a guideline/rule

6 views the guideline/rule.

Through the tool use, the designer is enabled to manage and to act on rules in different ways [as create, read, update and delete (CRUD), deploy and unbind]. Furthermore, the rules themselves can be managed by the user: definition, versioning and view are all action available to the user involved in the creation of the solution. Thus, if an user wants to use the create function, first of all he has to select between entering a new lean content design guideline (Figure 4) or rule (Figure 5). data:

In particular, for each guideline (Figure 4) the designer has to specify some basic

a if it is 'applied to' products or services components of a PSS; if it will be 'linked to' a specific product or service a reference is created between such guideline and the chosen element already available into the company's PLM system (if a PLM is used, it can be connected to the engineering environment and to the LDRT via a PSLM component) and/or other engineering environment components used to manage products and services data

b the 'definition', that is the content of the guideline to be created

c the 'ability' that is the function chosen to be enhanced for the solution through the DfPSSu approach

d the 'classification', that is to say the importance of the guideline to be followed

e the characterising 'tags' in order to foster their correct categorisation.

Instead, for each rule (Figure 5) the designer should specify the 'referring guideline' to which it is referred plus all the same fields reported above for guidelines (except the ability that is inherited by the referring guideline).

The set of features implemented rely on a data model that systematises the information needed for a complete definition and management of guidelines and rules. An overview of the core part of the underlying data model is provided in Figure 3. 
Figure 3 Data model core part overview extracted with MySQL workbench (see online version for colours)

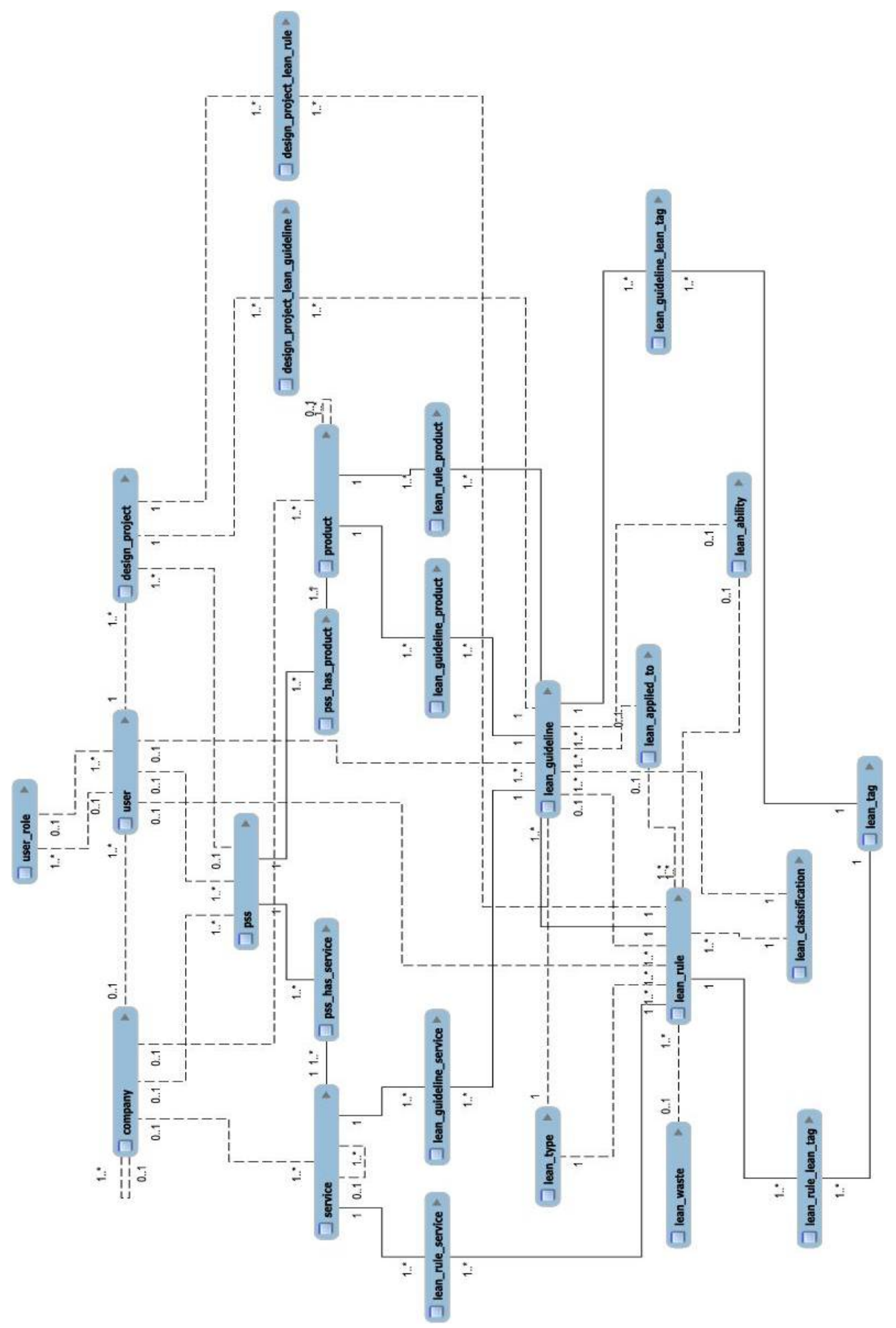


The fulcrum of the model is found in tables lean_guideline and lean_rule that represent the core concepts. These tables are linked by a dependency relationship to manage the content rule case, where each rule must have a guideline as reference. The association of guidelines/rules to products and services (and their components) under development is managed through the lean_guideline_service, lean_guideline_product, lean_rule_service and lean_rule product tables. Products and services are represented in the model by the namesake tables. In the top part of the model, the PSS, service, and product tables are obviously linked to allow an integrated PSS development. Lean rules and guidelines are also linked to the design_project concept through the design_project_lean_guideline and design project lean_rule tables: in this way it is possible to define which rules must be validated for a specific design project and if such rules have been satisfied (if the value of the checked attribute is properly set). Obviously the design_project is linked to the PSS under development. In the lower part of Figure 3, the lean_ability, lean_classification, lean_type, lean_waste are used to manage all other aspects of the Lean Design rules. At the end, in the lower right part of the model is represented the group of tables, i.e., lean_guideline_lean_tag, lean_rule_lean_tag and lean_tag, used for marking the guidelines and rules with a significant tag to improve future search and reuse of such data.

The open source MySQL database (Community Edition version), released under the GPL license, was selected for the data model implementation. The Lean Design rule tool, instead, is a SpringBoot application developed in Java EE. The tool is based on Spring MVC open source technologies, however all the business logic in the application has been developed from scratch for the DIVERSITY platform. All the software modules used are well-known and mature open source technologies.

Figure 4 LDRT - new lean content design guideline (see online version for colours)

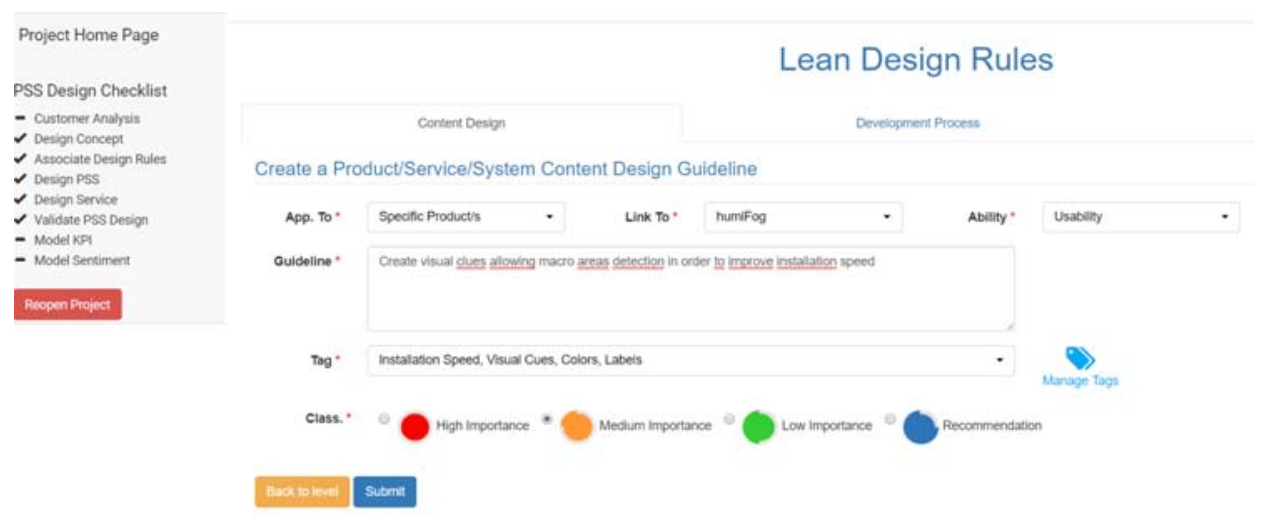

Moreover, a specific search page, allowing the user to search in the repository for the previously defined guidelines and/or rules, is also available and accessible from the main page of the tool: Figure 6 contains the user interface related to the LDRT search functionality. In particular, several filters are available to facilitate the search: the ID, the type, the definition, the user, the tag, the date, the classification, the ability, the applied to and the link to. 
Figure 5 LDRT - new lean content design rule (see online version for colours)

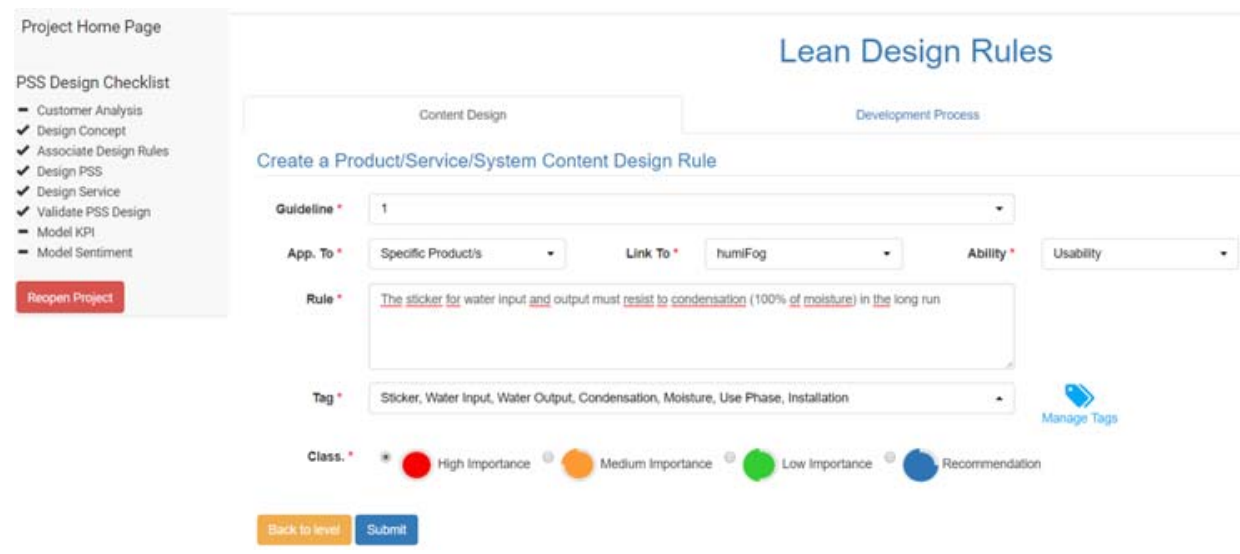

Figure 6 LDRT - guidelines and rules search (see online version for colours)

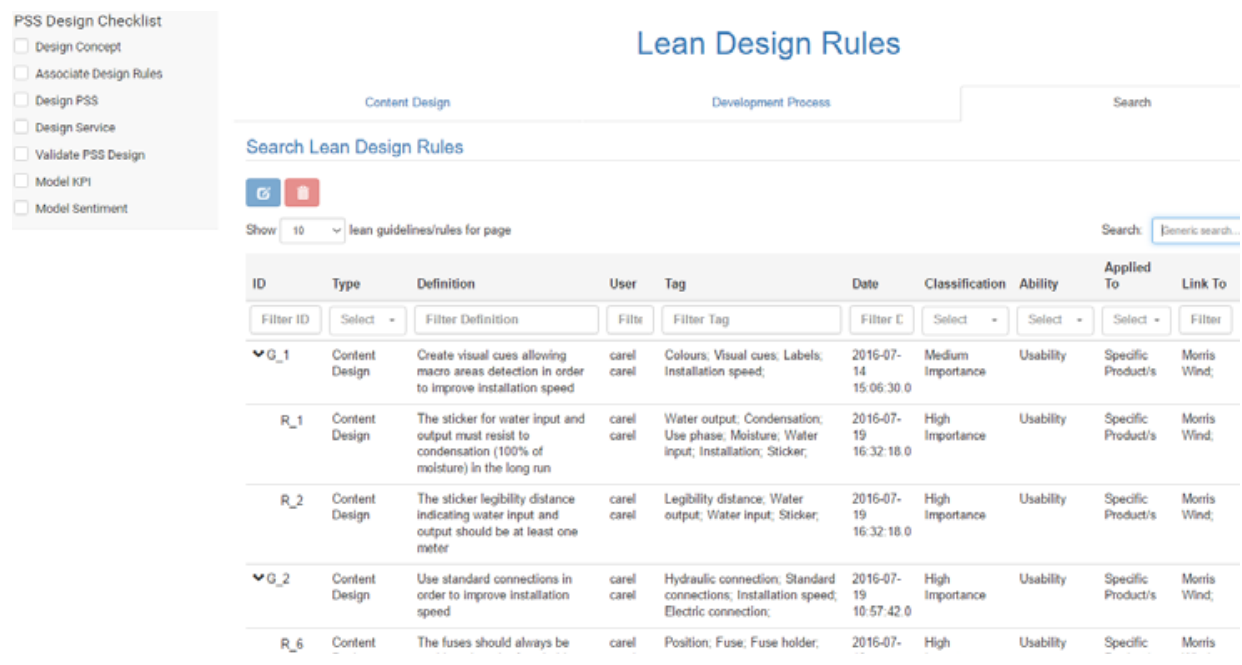

The figures listed in this section show the DIVERSITY Platform related to the LDRT. This tool can be used as standalone. However, to better exploit all the benefits deriving by the generation and use of guidelines and rules, the tool has been thought to interact with the PSS platform developed in the DIVERSITY project: in this way Lean Content Design guidelines and rules become the core pillar able to create a continuous stream of knowledge among the different stages of the PSS lifecycle, systematising product and service components in the PSS development process. Indeed, a bi-directional link is generated between the design knowledge and the PSS resources managed along the entire PSS lifecycle. To provide this kind of support, PDM and PLM systems have been integrated within the engineering environment because they are built on robust configuration management methodologies. Furthermore, a set of applications, called PSDM/PSLM tools, have been developed in order to interface the engineering environment with different PDM/PLM systems existing in the market. They are used to 
decouple the PSS design tool developed in the engineering environment by pre-existing business systems used to support the product development. The main features of these tools are the creation and management of specific PSS concepts into the underlying data model, the access to the information contained into the business systems, the start and management of approval workflows and the combined management of both product and service's development lifecycles. They offer controlled access of resources stored in PLM systems to the engineering environment tools, in particular, to the tool dealing with the conceptual phase [through product and service resources detected with the PSCT (Rondini et al., 2016)], to the service delivery process modelling tool (through physical evidences called along the process) and to the LDRT, dealing with the detailed design of the PSS and the generation of new design knowledge (Diversity Project, 2017). When a resource already exists within the business system, through the PSDM/PSLM tools it is possible to access all relevant information (name, description, version, relations, etc.) directly from the tools in the engineering environment, otherwise it is possible to start the process for the creation and definition of such resources. The information regarding the resources used in the development of products/services is saved and managed, so it is always possible to check the correct PSS configuration. Among these information, also the guidelines and rules are manageable through the PSDM/PSLM tools: indeed, for each resource, product, service or PSS, they can be retrieved or, if not existing, new knowledge can be linked to them.

The next section aims at explaining how this integration is valorised by the Lean Content Design guidelines and rules in the engineering environment, supported also by the PSDM/PSLM tools, giving continuity to the PSS development process, from the conception to the usage and service delivery phases.

\section{Design guidelines as the core pillar along the PSS engineering environment workflow}

Lean Content Design guidelines are practical recommendations provided to PSS developers able to improve the integration of product and service components and avoid wastes during the PSS development process. However, as argued in the following, they represent also a strategic and important connection point among the several stages composing the PSS development, articulated through the engineering workflow here proposed which is based on the PSSLDM methodology. This workflow, built to guide in a structured way the PSS development process, is composed of eight main steps:

1 customer analysis

2 design concept

3 associate design rules

4 design PSS

5 design service

6 validate PSS design

7 model KPI 
8 model sentiment.

The process starts with the customer analysis: KPIs and sentiment analysis monitoring data of PSS already on the market in the form of snapshot can be visualised. In this phase the design team can identify possible new customer or market trends and needs. The second phase is about the PSS concept: using the product service concept tree (PSCT) approach (Rondini et al., 2016), the PSS solution best suiting the company exigencies and the related needed resources (for both product and service) are identified and entered in the engineering environment. The resources here created are inserted and protocolled into the engineering environment so that they can also be associated to eventually existing design guidelines and, if a PLM system is used, through the PSLM component the created resources can be aligned to those available into such system. Thus, the third step is associate design rules: based on the solution previously defined, the design guidelines to be followed during the product design phase (normally conducted with the company's proprietary CAD/CAM tool) are selected among those already existing in the engineering environment through the LDRT. Otherwise, if the design team evaluates not sufficient the existing guidelines linked to the resources and suggested by the engineering environment, new consistent design guidelines can be generated: this happens when the knowledge already available in the LDRT is not appropriate to support the design of the solution. Thus, starting from generic guidelines (as already existing as new ones), new operative connected rules, more accurate for the design project under analysis, are defined and entered in the engineering environment in order to solve the PSS design issues raised. These rules are linked to a specific guideline. Then, stage 4, design PSS, is designated to support the detailed design phase of the overall PSS solution, providing a link between the company's systems used for product design (PDM, PLM or legacy systems) and the engineering environment used for PSS design. The BoM of the product, usually managed by PDM/PLM systems and designed using the company proprietary CAD/CAM tools, is made available into the engineering environment via the PSLM tool. Moreover, as explained above, the PLM, enriched with service functions, gives as a result the PSLM/PSDM tools. This allows to define the product (in the form of BoM) and the service (in the form of a process defined in the design service phase) composing the PSS, starting from the solution and resources selected in the design concept phase. Using the PSLM, the resources aimed at supporting the service provision along the process can be added and linked to the product's BoM, fostering the bond between the product and the service new knowledge in a sort of PSS BoM. In particular, during the stage 5, design service, the service delivery process is created [using business process management notation (BPMN) in the blueprinting structure] to define the service, also requiring to specify how the service resources (identified in the design concept) act along the service provision. Therefore, stage 6, validate PSS design, is performed after the PSS conceptualisation and the product and service design. Validation is done by checking the actual consideration of the mandatory design guidelines defined during the design phase. To do this, the list of guidelines selected for the design project in the associate lean rules stage is retrieved from the repository and listed in this stage. The user has to indicate manually every guideline actually considered in the design phase, using a particular attention to control to have followed all the mandatory guidelines. Moreover, under each guideline a sub-list of connected rules is shown. Furthermore, the user has to confirm to have considered at least one rule for every applied guideline. The project can be validated only if all the mandatory guidelines are checked. The system implements this control. 
Finally, once validated, the PSS design is saved in the PSS repository of the PSDM/PSLM. The following step, model KPI, is the selection of the KPIs to be associated to the just created PSS: they are identified and entered in the related tool of the engineering environment. This enables to associate them to the new PSS and to view graphically the KPIs and the PSS data. The final step of the workflow, model sentiment, involves the creation of a sentiment analysis model, using a consistent tool in the engineering environment to compute the PSS's sentiment: customers' feedbacks collection and analysis impel circularity, continuously improving the PSS design project through the use of the engineering environment.

Clearly the use of Lean Content Design guidelines and rules, managed through the LDRT and following such an engineering workflow, can boost the collaboration in a concurrent way of different functions of companies during the development of a PSS, thanks to an effective management of design knowledge. Resources, product and service configuration and design are all connected through a consistent use of the related design guidelines. Accordingly, product and service divisions are bridged not only during this critical phase but also the results of each PSS project developed in this way is destined to represent in future new wisdom available for the entire company to be easily shared and reused.

Finally, in order to obtain all these interacting tools integrated and embedded in the platform, they have been developed and validated, both singularly and from a platform view, following a well-structured procedure described in the next paragraph.

\section{LDRT validation}

The LDRT has been so far developed, used and validated in four companies: they are B2B SME companies, belonging to different countries and industrial sectors (heating, ventilation, air-conditioning and refrigeration; automation solutions for consumer product production; mould; commercial bakery machines). All the companies involved, even if they are characterised by a different adoption of technology at both product and process levels, are willing to go through the servitisation process, have a heavy weight design process and a mature and consolidated product portfolio, operate in different markets and their business is based upon the design and manufacturing of pure products.

The first three of them were also useful to evaluate the integration level among the different tools composing the engineering environment. Moreover, all the application cases were very useful to develop the final prototype of the LDRT according to an iterative continuous improvement process to be tested in real-world settings, similar and inspired to the systems development field (Nunamaker and Chen, 1990). Thanks to this, several feedbacks and organisational issues related to the tool adoption, were detected and collected. Also an online questionnaire was used to get from practitioners a technical evaluation of the tool in terms of functionality and to better understand its strengths and weaknesses. All the feedbacks obtained have been grouped into four areas: methodology benefits, tool benefits, organisational and system adoption issues, methodology and tool issues. The specific inputs from the different cases were compared and summed up in more general categories and used to assess the methodology and the tool according to the DfX tool requirements defined in Huang and Mak (1997). 
Among the several feedbacks received, a practical issue was considered for the daily use of the tool in the company. A continuous check could be needed in order to manage knowledge redundancy or to contrast wrong indications for designers. From an organisational point of view, this issue is related to the identification of who is responsible, in the design team, of protocolling and managing the produced knowledge. The profile of the design manager is the most indicated to finally assess and approve the data previously inserted by designers and engineers on the tool during the design process, also checking possible overlapping with already existing knowledge. He has a paramount view of both the design process and knowledge and they are also in charge of coordinating the different divisions' constraints with designers and engineers' ideas and actions. As a result, he is in charge of coordinating a multidisciplinary group with the final aim of generating worth design guidelines and rules.

Furthermore, as stated above, it has been considered that the user responsible of inserting on the tool all the guidelines and rules generated through the methodology, the designer or engineer, is supposed to sustain a big effort for this activity. Dealing with this, an important point was raised in the last case for the future researches: the enhancement of the integration degree between the PSS design GuRu methodology and the Lean Design rule tool. New functionalities supporting the methodology conduction would indeed automatise the insertion process of the created guidelines and rules, requiring hence less effort for designers and engineers along the PSS development process.

However, once such design knowledge is approved, its actual effectiveness and usefulness should be measured through a set of key performance indicators (KPIs). KM can be defined as the creation, acquisition, sharing, and utilisation of knowledge for the promotion of organisational performance (Bassi, 1997). The measurement of KM effectiveness could be useful to evaluate if the results of this research actually work. Such measures need to be focused on potential problems in the knowledge creation and utilisation processes. Some examples could be the knowledge stagnation in the knowledge creation process, the number of redesign/reworks of a PSS design project, the degree of reuse of guidelines or the generalisability degree of guidelines.

Finally, in order to achieve the system development full prototype, this research has been tested and validated using a sufficient number and wide spectrum of illustrative and field improvement test cases with full technical and managerial support. Moreover, as also stated by Huang and Mak (1997), a verification with academic expert has been relevant to verify its overall value.

\section{Conclusions and further researches}

This research was mainly aimed at raising the awareness and at starting proposing the possible changes needed by both current design and PLM models when they have to deal with PSSs. In this direction, the LDRT has been proposed to support the entire PSS development process, guaranteeing the knowledge sharing among product and service design functions. Thanks to Lean Content Design guidelines and rules, used as a strategic connecting point along the entire engineering workflow, a platform oriented approach, integrated with PLM systems, has been introduced and fully exploited in the PSS context. 
One of the triggers of this research was the combination of two different approaches, lean and DfX, with the final objective of enhancing the PSS through making the product components more suitable to support the service features since the beginning of its development process. Indeed, this research stream, comprising both the methodology and tool generating and managing Lean Content Design guidelines and rules, follows the lean thinking philosophy, which is a business approach aimed to provide a new way to think about how to organise human activities to deliver more benefits to society and value to individuals while eliminating waste (Sassanelli et al., 2015a, 2015b). Reduce the waste means to obtain a product/service more efficient, to reduce the cost of production and achieve a better position in the market. The use of the tool enables to understand how to add value not only to the PSS but also to the process needed to its development reducing the issues due to wrong interpretations or to the creation of solutions not compliant with what required. This heavily affects the customer perception of the company, fostering the customer loyalty and also the company performances. Indeed, the advantage is not to be identified exclusively on the product/service but to the entire enterprise system. The designer, through the LDRT, easily retrieve tacit knowledge in organisations, gathered through company practice and experience along all the PSS lifecycle. The power of the tool is that a designer is not obliged to possess deep knowledge of the lean philosophy in order to adapt his design activities in this direction, because the tool supports the user and incorporates this methodology as a black box. Moreover, a platform, which will incorporate all these rules to guide the designer at all stages of PSS lifecycle design, is provided to the user. This platform, based on methods supporting the different phases of the PSS lifecycle, comprises tools for the identification, generation, use and re-use of new design guidelines and rules, taking into account feedbacks from customers, designers and shop-floor experts. In this context, the engineering workflow proposed in Section 5 has a strategic role: it guides designer and engineers from the concept phase to the final design and configuration of the PSS, fully exploiting the integration, enabled by the PSDM/PSLM tools, of design guidelines and rules with data existing in PLM systems.

The effective generation, use and re-use of design guidelines and rules, fostered by the IT tools proposed in this work, can also enable a service and sector specific provision of knowledge. This can contribute to provide an IT repository DfPSSu manual always more suitable to each manufacturer willing to navigate towards the servitisation phenomenon.

Finally, as reported in Section 6, some feedbacks were obtained during the validation phase in the four conducted application cases. This opens the room to further developments to enhance the tool functionalities: an important step could be to enable the tool in supporting also the conduction of the PSS design GuRu methodology. This new function would automatise not only the provision of a summary report at its end but also the process needed to develop and insert the knowledge in the tool repository.

Another aspect should also be considered: the further exploitation of the integration between the LDRT and the PLM systems: the capacity of using rules to generate product design, known as knowledge-based engineering (KBE), can constitute indeed an important bond between the different IT systems used in the company (PLM, CAx, ERP). Directly deriving from the KM, KBE represents the practical technological application on the engineering, operatively addressing the vision and strategy delineated with the Lean Content Design guidelines and rules generation. 


\section{Acknowledgements}

This work was funded by the European Commission through Diversity Project (Cloud Manufacturing and Social Software Based Context Sensitive Product-Service Engineering Environment for Globally Distributed Enterprise), GA 636692. It is a European project funded under the H2020 program, started in February 2015 and planned to finish in January 2018.

\section{References}

Ackoff, R.L. (1989) 'From data to wisdom', Journal of Applied Systems Analysis, Vol. 16, No. 1, pp.3-9.

Bassi, L.J. (1997) 'Harnessing the power of intellectual capital', Training \& Development, Vol. 51, No. 12 , p.25 [online] http://proquest.umi.com/pqdweb?did=23958702\&Fmt=7\&clientId= $11502 \& \mathrm{RQT}=309 \& \mathrm{VName}=\mathrm{PQD}$.

Bauer, S. and Paetzold, K. (2006) 'Influence of DFX criteria on the design of the product development process', Proceedings of the 6th Integrated Product Development Workshop (IPD 2006), Vol. 5, pp.1-8.

Brax, S. (2005) 'A manufacturer becoming service provider - challenges and a paradox', Managing Service Quality: An International Journal, April, Vol. 15, No. 2, pp.142-155 [online] http://www.emeraldinsight.com/doi/10.1108/09604520510585334 (accessed 8 March 2017).

Cenamor, J., Rönnberg Sjödin, D. and Parida, V. (2017) 'Adopting a platform approach in servitization: leveraging the value of digitalization', International Journal of Production Economics, Vol. 192, No. C, pp.54-65 [online] http://linkinghub.elsevier.com/retrieve/pii/ S0925527316304236.

Chiu, M-C. and Okudan, G.E. (2010) 'Evolution of Design for X tools applicable to design stages: a literature review', Proceedings of the ASME 2010 International Design Engineering Technical Conferences \& Computers and Proceedings of the ASME 2010 International Design Engineering Technical Conferences \& Computers and Information in Engineering Conference, pp.1-12.

Corallo, A., Latino, M.E., Lazoi, M., Lettera, S., Marra, M. and Verardi, S. (2013) 'Defining product lifecycle management: a journey across features, definitions, and concepts', ISRN Industrial Engineering, Vol. 2013, No. 24 [online] http://www.hindawi.com/journals/isrn/ 2013/170812/ (accessed 11 February 2017).

Demarco, T. and Lister, T. (1987) Peopleware: Productive Projects and Teams, DorsetHousePublishing Co., New York.

Diversity Project (2016) D1.4 Public System Concept [online] https://www.diversity-project.eu/ ?page_id=3378.

Diversity Project (2017) D2.1 Specification of the DIVERSITY Methodology and of Lean Design and Visualization Tool [online] https://www.diversity-project.eu/?page_id=3378.

Dombrowski, U. and Schmidt, S. (2013) 'Integration of Design for X approaches in the concept of lean design to enable a holistic product design', in Industrial Engineering and Engineering Management (IEEM), IEEE, pp.1515-1519.

Dombrowski, U., Schmidt, S. and Schmidtchen, K. (2014) 'Analysis and integration of Design for $\mathrm{X}$ approaches in lean design as basis for a lifecycle optimized product design', Procedia CIRP, Vol. 15, pp.385-390 [online] http://dx.doi.org/10.1016/j.procir.2014.06.023.

Duffey, M.R. and Dixon, J.R. (1993) 'Managing the product realization process: a model for aggregate cost and time-to-market evaluation', Concurr. Eng. Res. Appl., Vol. 1, No. 1, pp.51-59.

Ellström, P-E. (2007) 'Knowledge creation through interactive research: a learning perspective', in HSS-07 Conference, pp.1-12. 
Garetti, M., Rosa, P. and Terzi, S. (2012) 'Life cycle simulation for the design of product-service systems', Computers in Industry, May, Vol. 63, No. 4, pp.361-369 [online] http://linkinghub.elsevier.com/retrieve/pii/S0166361512000413 (accessed 5 August 2014).

Gatenby, D.A. and Foo, G. (1990) 'Design for X (DFX): key to competitive, profitable products', AT\&T Technical Journal, Vol. 69, No. 3, pp.2-13 [online] http://dx.doi.org/10.1002/j.15387305.1990.tb00332.x.

Goedkoop, M., Van Halen, C., te Riele, H.R.M. and Rommens, P.J.M. (1999) Product Service Systems, Ecological and Economic Basics, Report for Dutch Ministries of Environment (VROM) and Economic Affairs (EZ), Vol. 36, No. 1, pp.1-122.

Grover, V. and Davenport, T.H. (2001) 'General perspectives on knowledge management: fostering a research agenda', Journal of Management Information Systems, Vol. 18, No. 1, pp.5-21 [online] http://www.scopus.com/inward/record.url?eid=2-s2.0-0034894493\& partnerID=tZOtx3y1.

Hepperle, C., Biedermann, W., Böcker, A. and Lindemann, U. (2011) 'Design for X-guidelines and lifecycle phases with relevance for product planning - an MDM-based approach', Proc. 13th Int. DSM Conf., pp.215-220.

Huang, G.Q. (1996) Design for X - Concurrent Engineering Imperatives, Springer, Dordrecht.

Huang, G.Q. and Mak, K.L. (1997) 'The DFX shell: a generic framework for developing Design for X tools', Robotics \& Computer-Integrated Manufacturing, Vol. 13, No. 3, pp.271-280.

Huthwaite, B. (2012) The Lean Design Solution: A Practical Guide to Streamlining Product Design and Development, Institute for Lean Design, Mackinac Island.

Meiren, T. and Burger, T. (2008) 'ServLab: visualising and simulating new services', Conference proceedings in New Horizons for the role and production of services, RESER 2008, Stuttgart, Germany, 25-26 September 2008.

Mital, A., Desai, A., Subramanian, A. and Mital, A. (2008) Product Development: A Structured Approach to Consumer Product Development, Design, and Manufacture, Butterworth-Heinemann, Elsevier, Burlington, USA [online] http://www.sciencedirect.com/ science/article/pii/B9780750683098500030.

Mont, O. and Lindhqvist, T. (2003) 'The role of public policy in advancement of product service systems', Journal of Cleaner Production, Vol. 11, No. 8, pp.905-914.

Moxham, C. (2005) 'The lean design guidebook: everything your product development team needs to slash manufacturing cost', International Journal of Operations \& Production Management, Vol. 25, No. 9, pp.938-938 [online] http://www.emeraldinsight.com/doi/10.1108/ 01443570510613974 (accessed 24 July 2017).

Nunamaker Jr., J.F. and Chen, M. (1990) 'Systems development in information systems research', Proceedings of the Twenty-Third Annual Hawaii International Conference on System Sciences, Vol. 3, pp.631-640 [online] http://ieeexplore.ieee.org/xpls/abs_all.jsp?arnumber= 205401.

Pezzotta, G., Pinto, R., Pirola, F. and Ouertani, M-Z. (2014) 'Balancing product-service provider's performance and customer's value: the service engineering methodology (SEEM)', Procedia CIRP, Vol. 16, No. 31, pp.50-55 [online] http://linkinghub.elsevier.com/retrieve/pii/ S2212827114000936 (accessed 5 September 2014).

Pezzotta, G., Sala, R., Pirola, F., Campos, A.R., Margarito, A., Correia, A.T., Fotia, S. and Mourtzis, D. (2016) 'Definition of a PSS engineering environment: from the theoretical methodology to the platform implementation', in XXI Summer School 'Francesco Turco', 1315 September.

Potts, C. (1993) 'Software-engineering research revisited', IEEE Softw., Vol. 10, No. 5, pp.19-28.

Rondini, A., Pezzotta, G., Pirola, F., Rossi, M. and Pina, P. (2016) 'How to design and evaluate early PSS concepts: the product service concept tree', in Procedia CIRP, pp.366-371 [online] http://dx.doi.org/10.1016/j.procir.2016.04.177. 
Roucoules, L. and Tichkiewitch, S.(2015) 'Knowledge synthesis by least commitment for product design', in CIRP Annals, Elsevier, pp.141-144 [online] http://www.sciencedirect.com/science/ article/pii/S000785061500030X (accessed 2 October 2017).

Sakao, T., Shimomura, Y., Sundin, E. and Comstock, M.(2009) 'Modeling design objects in CAD system for service/product engineering', Comput. Des., Vol. 41, No. 41, pp.197-213 [online] http://dx.doi.org/10.1016/j.cad.2008.06.006.

Sassanelli, C., Pezzotta, G., Pirola, F., Terzi, S. and Rossi, M. (2016) 'Design for product service supportability (DfPSS) approach: a state of the art to foster product service system (PSS) design', in Procedia CIRP, pp.192-197 [online] http://dx.doi.org/10.1016/j.procir.2016.03. 233.

Sassanelli, C., Pezzotta, G., Rossi, M., Terzi, S. and Cavalieri, S. (2015a) 'Towards a lean product service systems (PSS) design: state of the art, opportunities and challenges', in Procedia CIRP, Elsevier B.V., pp.191-196 [online] http://linkinghub.elsevier.com/retrieve/pii/ S2212827115003534.

Sassanelli, C., Terzi, S., Pezzotta, G. and Rossi, M. (2015b) 'How lean thinking affects product service systems development process', in XX Summer School Francesco Turco 2015 Operational Excellence Experiences, pp.97-104 [online] http://www.summerschoolaidi.it/images/Naples2015/proceed/15_sassanelli.pdf.

Sassanelli, C., Pezzotta, G., Sala, R., Correia, A. and Terzi, S. (2017a) 'Testing the methodology to generate design for product service supportability (DfPSS) guidelines and rules: an application case', in Procedia CIRP, pp.265-270.

Sassanelli, C., Pezzotta, G., Sala, R., Koutopes, A. and Terzi, S. (2017b) 'The design for product service supportability (DfPSSu) methodology: generating sector-specific guidelines and rules to improve product service systems (PSSs)', in Ríos, J., Bernard, A., Bouras, A. and Foufou, S. (Eds.): Product Lifecycle Management and the Industry of the Future, PLM 2017, IFIP Advances in Information and Communication Technology, Vol. 517, Springer, Cham.

Savino, M.M. and Mazza, A. (2012) 'PLM maturity model: a multi-criteria assessment in southern Italy companies', International Journal of Operations and Quantitative Management, Vol. 18, No. 3, pp.159-179 [online] https://www.researchgate.net/profile/Matteo_Savino/publication/ 256080629_PLM_Maturity_Model_A_Multi-Criteria_Assessment_in_Southern_Italy_ Companies/links/0046352177f1b3f23a000000/PLM-Maturity-Model-A-Multi-CriteriaAssessment-in-Southern-Italy-Companies.p (accessed 2 October 2017).

Schenk1, S.A., Schmidt, D.M., Schockenhoff, D. and Maurer, M. (2014) 'Knowledge evaluation for PSS providers', in Procedia CIRP, pp.86-91 [online] http://linkinghub.elsevier.com/retrieve/ pii/S2212827114000997 (accessed 15 February 2017).

Sundin, E. (2009) 'Life-cycle perspectives of product/service-systems: in design theory', in Introduction to Product/Service-System Design, pp.31-49.

Tan, A.R., Matzen, D., McAloone, T.C. and Evans, S. (2010) 'Strategies for designing and developing services for manufacturing firms', CIRP J. Manuf. Sci. Technol., Vol. 3, No. 2, pp.90-97 [online] http://www.scopus.com/inward/record.url?eid=2-s2.0-78649847538\& partnerID=tZOtx3y1.

Tukker, A. and Tischner, U. (2006) 'Product-services as a research field: past, present and future. Reflections from a decade of research', J. Clean. Prod., January, Vol. 14, No. 17, pp.1552-1556 [online] http://linkinghub.elsevier.com/retrieve/pii/S0959652606000862 (accessed 18 July 2014).

Vandermerwe, S. and Rada, J. (1988) 'Servitization of business: adding value by adding services', Eur. Manag. J., Vol. 6, No. 4, pp.314-324.

Wallin, J., Chirumalla, K. and Thompson, A. (2013) 'Developing PSS concepts from traditional product sales situation: the use of business model canvas', in Proceedings 5th CIRP Industrial Conference Product-Service Integration for Sustainable Solutions, pp.263-274, Springer, Berlin, Heidelberg [online] http://link.springer.com/10.1007/978-3-642-30820-8_23 (accessed 15 February 2017). 
Williamson, K. (2002) Research Methods for Students, Academics and Professionals, Quick Print, Wagga Wagga.

Winner, R., Pennell, J., Bertrand, H. and Slusarczuk, M.(1988) The role of Concurrent Engineering in Weapons System Acquisition, Institute for Defense Analyses, R-338, Alexandria, Virginia [online] http://oai.dtic.mil/oai/oai?verb=getRecord\&metadataPrefix=html\&identifier $=$ ADA203615. 